\title{
Analysis of disease patterns and cost of treatments for prevention of deep venous thrombosis after total knee or hip replacement: results from the Practice Analysis of THromboprophylaxis after Orthopaedic Surgery (PATHOS) study
}

\author{
Luca Degli Esposti' \\ Guido Didoni² \\ Teresa Simon ${ }^{3}$ \\ Stefano Buda' \\ Diego Sangiorgi' \\ Ezio Degli Esposti' \\ 'CliCon Health, Economics and \\ Outcomes Research, Ravenna, Italy; \\ ${ }^{2}$ BMS Italy, Rome, Italy; ${ }^{3}$ BMS Global, \\ Princeton, NJ, USA
}

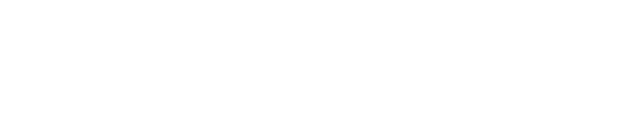

Introduction: Venous thromboembolism (VTE) is a well-known complication of total hip replacement (THR) and total knee replacement (TKR). Various drugs have been introduced in an attempt to reduce the mortality as well as the short-term and long-term morbidity associated with the development of VTE. The aim of this study was to analyze drug utilization for thromboprophylaxis and the cost of illness in real clinical practice in patients with THR or TKR.

Materials and methods: A multicenter, retrospective, observational cohort study based on local health unit administrative databases was conducted. All patients ( $\geq 18$ years old) discharged for THR/TKR procedures between January 1, 2007 and December 31, 2008 were included in the study. The date of first hospital discharge was the index date; patients were followed up for a period of 12 months.

Results: A total of 10,389 patients were included: 3516 males (33.8\%, $69.4 \pm 10.4$ years) and 6873 females $(66.2 \%, 71.7 \pm 9.0$ years), of which $5483(52.8 \%)$ were discharged for THR and $4906(47.2 \%)$ for TKR. First antithrombotic treatments after discharge were enoxaparin (3937, 37.9\%), heparin $(3752,36.1 \%)$, antiplatelet agents $(658,6.3 \%)$, vitamin $\mathrm{K}$ antagonists (276, 2.7\%), fondaparinux (136, 1.3\%), combinations $(185,1.8 \%)$, and no therapy $(1445,13.9 \%)$. Overall, we observed 2347 (22.6\%) treatment changes; median duration of antithrombotic treatment was 23 days (range 11-47) for THR and 22 days (range 11-46) for TKR. During the follow-up period, we observed 129 cases of VTE (120 per 10,000 patients), five post-thrombotic syndrome (4.8 per 10,000 patients), and three heparin-induced thrombocytopenia ( 2.9 per 10,000 patients). Median cost for both THR and TKR was $€ 9052.00$ (range $€ 8063.00-€ 9084.96$ ), with a median length of stay of 9.0 days (range 6.0-12.0).

Keywords: venous thromboembolism, VTE, total hip replacement, THR, total knee replacement, TKR, real practice, cost of illness, antithrombotic therapy

\section{Introduction}

Venous thromboembolism (VTE) is a complication that can occur after total hip-replacement (THR) or knee-replacement (TKR) surgery. The literature reports an incidence of events that reaches $2.7 \% .{ }^{1-4}$ Two different forms exist: deep vein thrombosis (DVT) and pulmonary embolism (PE). ${ }^{5}$ Prophylactic drug treatment after discharge from 
the hospital aims to reduce morbidity and mortality events associated with DVT and PE events. ${ }^{6-11}$ This preventive drug treatment may be applied up to 3-6 months after the hospital discharge in relation to the patient's risk factors. ${ }^{12}$ Treatment with heparin poses problems for prolonged treatment, ie, thrombocytopenia, ${ }^{13}$ whereas treatment with vitamin $\mathrm{K}$ antagonists (VKAs) has a large number of issues related to the management of treatment-related risk of bleeding, requiring the patient to be followed by specialized centers. ${ }^{14}$ Despite the problems briefly described, treatment with anticoagulants is essential for the prevention of morbidity and mortality events associated with THR and TKR surgery. ${ }^{6,15}$

The primary objective of the study was to describe antithrombotic utilization during the 6 months after hospital discharge (ie, heparin, VKAs, or a combination) and the subsequent treatment pattern (eg, incidence of switches); moreover, we would like to assess, within 6 months after hospital discharge, the morbidity associated with the procedure in analysis; in relation to the latter, a secondary objective was to calculate the cost of illness in terms of direct costs (ie, pharmacological treatments, diagnostic tests, specialist visits, and hospitalizations) associated with the THR/TKR procedure.

\section{Materials and methods}

\section{Data source}

The study subjects were enrolled from individuals registered with a large-population administrative database comprising seven local health units (LHUs) (approximately 3.5 million health-assisted individuals). The LHU, being a point of delivery for the National Health Service, which is a nonprofit health-care system, has an information network that routinely measures the volume of expenditure generated by the dispensing of medications to registered patients. In particular, this administrative/accounting-type archive is used conventionally for recording the amounts that pharmacies are entitled to receive from the LHU by way of refund in respect of medications reimbursable by the public finance and dispensed free of charge. The prescriptions recorded are attributed in each case to the patient recipient. The identification of the patient given by the personal health number, cross-checked with the registry office, the hospital database and the diagnostic tests and specialist visits database allows the information on medication refills to be integrated with date of birth, sex, any record of hospitalization, diagnostic test, and specialist visit.

In particular, the following databases were used: the Health-Assisted Subjects' Database, containing patients' demographic data; the Medications Prescription Database, providing information for each medication prescription, such as the prescribing physician's number, the Anatomical Therapeutic Chemical (ATC) classification system code of the drug purchased, the number of packs, the number of units per pack, the dosages, the unit cost per pack, and the prescription date; the Hospital Discharge Database, containing information on discharge for each hospitalization, in particular the date of admission and discharge, main and accessory diagnosis, coded according to the International Classification of Diseases, ninth revision, clinical modification (ICD-9 CM); and Ambulatory Care Specialist, which records outpatient specialist services (visits, laboratory tests, diagnostic tests) provided to the patient, such as the type of visit and the date of the visit.

The patient code in each database permitted electronic linkage between all databases. In order to guarantee patient privacy, each subject was assigned an anonymous univocal numeric code. No identifiers related to patients were provided to the researchers. The local ethics committee of each participating LHU approved this study.

\section{Patients in analysis}

Patients $\geq 18$ years were enrolled if they were discharged for THR (ICD9 code 81.51) or TKR (ICD9 code 81.54) between January 1, 2007 and December 31, 2008 (enrollment period). The enrollment date of each subject was defined as the earliest date within the enrollment period in which the patient was discharged for one of the two procedures in analysis; starting from this date, the individual patient was followed for one year, while the year before the enrollment date was used to characterize the patient (eg, diagnosis, treatment, comorbidities); no patients with both procedures relating to the same index hospitalization were detected, and consequently the two groups were mutually identified as exclusive. Patients transferred to another LHU during the whole observation period (previous year and follow-up period) were excluded from analysis.

\section{Patient characteristics}

Patients in analysis were characterized according to hospital admissions, outpatient visits, prescribed drugs during the follow-up period and the characterization period; specifically, the treatments of interest were antithrombotic treatment (VKAs [ATC B01AA], heparin [ATC B01AB], plateletaggregation inhibitors excluding heparin [ATC B01AC], other [ATC B01A, excluding ATC codes mentioned before]), antihypertensive drugs (ATC C02, C03, C07, C08, C09), 
anti-inflammatory drugs (ATC M01), corticosteroids (ATC $\mathrm{H} 02$ ), other cardiovascular drugs (ATC C01, C04, C05, C10), and medications for diabetes (ATC A10).

Hospitalizations related to THR/TKR were identified by ICD 9 codes (primary or accessory discharge reasons); in particular, we identified VTE (ICD9-CM codes 452-453.9), PE (ICD9-CM code 415.1), postphlebitic syndrome (PTS, ICD9-CM code 459.1), heparin-induced thrombocytopenia (HIT, ICD9-CM codes 287.4, 287.5), hospitalizations for bleedings ${ }^{16,17}$ (intracranial bleeds [ICD9-CM codes 430-432], gastrointestinal bleeds [ICD9-CM codes 456.0, 531.0, 531.2, 531.4, 531.6, 532.0, 532.2, 532.4, 532.6, 533.0, 533.2, 533.4, 533.6, 534.0, 534.2, 534.6, 568.3, 578.0, 578.9], urinary tract bleeding [ICD9-CM codes 596.7, 599.7], uterus bleeding [ICD9-CM codes 626.5, 626.6, 626.9, 627.0, 627.1], vaginal bleeding [ICD9-CM codes 623.8, 626.2]; epistaxis [ICD9-CM code 784.7], hemoptysis [ICD9-CM code 786.3], hemorrhage not otherwise specified [ICD9-CM code 459.0], hemarthrosis [ICD9-CM code 719.1], hemopericardium [ICD9-CM code 423.0], bleeding into corpus vitreum [ICD9-CM code 379.23], traumatic subdural bleeding [ICD9-CM code 852.2], bleeding or hematoma as a complication of a surgery [ICD9-CM code 998.1], and rupture of a wound surgery [ICD9-CM code 998.3]). In addition to these, all hospitalizations for cardiovascular reasons were considered: heart failure (ICD9-CM code 428), ischemic heart disease (ICD9-CM codes 410-414), cerebrovascular disease (ICD9-CM codes 430-438), and other cardiovascular events (ICD9-CM codes 390-459, other than before mentioned). Moreover, in order to characterize the patients in analysis, hospitalizations for kidney diseases (ICD9-CM codes 580-589) and ulcers (ICD9-CM codes 531-534, $569.41,569.82)$ were considered.

\section{Costs}

Costs were reported in euros. The approximate rate during the enrollment period between euros and US dollars was 0.8 . The costs for hospitalizations, treatments, and outpatient specialist services were classified as related and not related to the surgical procedures in analysis. Related THR/TKR costs refer to antithrombotic treatments, outpatient services such as postoperative visit, ultrasound, magnetic resonance, $\mathrm{Rx}$, ecocolordoppler, D-dimer, complete blood count, fibrinogen, prothrombin time, partial thromboplastin time, and movement reeducation. With regard to hospitalizations, the cost of the THR or TKR procedure was considered, and if any, hospitalizations for PE, VTE, PTS, HIT, cardiovascular events, renal diseases, and ulcers occurred during the first
6 months of follow-up. The cost for each hospitalization was obtained from DRG codes. THR/TKR procedures were identified by the same DRG code (209, major joint/limb reattachment procedure), and consequentially they had the same cost.

\section{Statistical analysis}

Continuous variables were reported as mean and standard deviation (median and range as appropriate), whereas categorical variables were expressed as numbers and percentages. When comparisons were made, groups were assessed and compared using $t$-tests and chi-square tests, respectively. Two-tailed $P$-values less than 0.05 were considered significant. All analysis was performed using SPSS for Windows, version 18.0 (IBM, Armonk, NY, USA).

\section{Results}

A total of 10,389 patients were included: 6873 females (66.2\%, age $71.7 \pm 9.0$ years) and 3516 males (33.8\%, age $69.4 \pm 10.4$ years). A total of 5483 patients were hospitalized for THR (52.8\%) and 4906 patients for TKR (47.2\%). During the year of characterization, 9572 patients (92.1\%) did not experience any hospital admission, 540 (5.2\%) were hospitalized for cardiovascular reasons, $210(2.0 \%)$ for ulcers, and $67(0.6 \%)$ had other type of hospital admissions.

As regards treatments prior to the enrollment date, the most prescribed drugs were anti-inflammatory agents in combination with antihypertensives (3212 patients, 30.9\%), antihypertensives alone (1541,14.8\%), anti-inflammatory agents $(1534,14.8 \%)$, anti-inflammatory agents and corticosteroids and antihypertensives (896, 8.6\%), anti-inflammatory agents and corticosteroids (412, 4.0\%), anti-inflammatory agents and antihypertensives and cardiovascular therapy $(412,4.0 \%)$; no previous treatment was found among 1537 patients (14.8\%) (Table 1). The total length of stay of the enrollment hospitalization was $10.4 \pm 8.0$ days for THR (median 9, range 6-12) and 9.2 \pm 5.0 days for TKR (median 9, range 6-10) $(P<0.001)$.

The first antithrombotic treatments prescribed at discharge during the first 6 months of follow up were found to be enoxaparin in 3937 patients (37.9\%), heparin (3752, $36.1 \%)$, antiplatelet agents $(658,6.3 \%)$, VKA $(276,2.7 \%)$, fondaparinux (136,1.3\%), combination of at least two of the previous $(185,1.8 \%)$; no therapy was found among 1445 patients (13.9\%); overall, 2347 (22.6\%) changes of therapy were observed (Table 2).

The median duration of antithrombotic treatment during the post discharge period was 23 days (range 11-47) for 
Table I Demographic characteristics

\begin{tabular}{|c|c|}
\hline $\mathrm{n}$ & 10,389 \\
\hline Males (n, \%) & $3516(33.8 \%)$ \\
\hline Age (years, mean $\pm S D$ ) & $70.9 \pm 9.5$ \\
\hline THR/TKR procedure & $\begin{array}{l}5483(52.8 \%) / 4906 \\
(47.2 \%)\end{array}$ \\
\hline \multicolumn{2}{|l|}{ Previous hospital admissions } \\
\hline Cardiovascular reasons & $540(5.2 \%)$ \\
\hline Ulcer & $210(2.0 \%)$ \\
\hline Other & $67(0.6 \%)$ \\
\hline No previous hospital admission & $9572(92.1 \%)$ \\
\hline \multicolumn{2}{|l|}{ Previous treatments (more frequent combinations) } \\
\hline Anti-inflammatory agents + antihypertensives & $3212(30.9 \%)$ \\
\hline Antihypertensives & I54I (I4.8\%) \\
\hline Anti-inflammatory agents & $1534(14.8 \%)$ \\
\hline $\begin{array}{l}\text { Anti-inflammatory agents }+ \text { corticosteroids } \\
+ \text { antihypertensives }\end{array}$ & $896(8.6 \%)$ \\
\hline Anti-inflammatory agents + corticosteroids & $4 I 2(4.0 \%)$ \\
\hline $\begin{array}{l}\text { Anti-inflammatory agents + antihypertensives } \\
+ \text { cardiovascular therapy }\end{array}$ & $412(4.0 \%)$ \\
\hline No previous treatment & $1537(\mid 4.8 \%)$ \\
\hline
\end{tabular}

Abbreviations: THR, total hip replacement; TKR, total knee replacement; SD, standard deviation.

THR and 22 days (range 11-46) for TKR; mean values were, respectively, $37.8 \pm 42.3$ and $37.6 \pm 42.1$. Specifically, these durations of treatment were, respectively, $29.0 \pm 48.5$ and $30.0 \pm 42.1$ for enoxaparin, $33.0 \pm 23.2$ and $25.0 \pm 15.5$ for fondaparinux, $30.0 \pm 38.8$ and $30.0 \pm 40.1$ for other heparins.

Table 2 First prescription of antiplatelet therapy during the first 6 months of follow-up and treatment changes

\begin{tabular}{|c|c|c|c|c|}
\hline & \multirow[t]{2}{*}{$\mathbf{n}$} & \multirow[t]{2}{*}{$\%$} & \multicolumn{2}{|c|}{$\begin{array}{l}\text { Patients with a } \\
\text { treatment change }\end{array}$} \\
\hline & & & $n$ & $\%$ \\
\hline \multicolumn{5}{|l|}{ THR } \\
\hline No AT use & 828 & $15.1 \%$ & - & - \\
\hline Heparin & 1760 & $32.1 \%$ & 454 & $25.8 \%$ \\
\hline Enoxaparin & 2224 & $40.6 \%$ & 502 & $22.6 \%$ \\
\hline Antiplatelet & 362 & $6.6 \%$ & 64 & $17.7 \%$ \\
\hline VKAs & 135 & $2.5 \%$ & 17 & $12.6 \%$ \\
\hline Fondaparinux & 70 & $1.3 \%$ & 22 & $31.4 \%$ \\
\hline Combination & 104 & $1.9 \%$ & 99 & $95.2 \%$ \\
\hline Total & 5483 & & II 58 & $21.1 \%$ \\
\hline \multicolumn{5}{|l|}{ TKR } \\
\hline No AT use & 617 & $12.6 \%$ & - & - \\
\hline Heparin & 1992 & $40.6 \%$ & 527 & $26.5 \%$ \\
\hline Enoxaparine & 1713 & $34.9 \%$ & 463 & $27.0 \%$ \\
\hline Antiplatelet & 296 & $6.0 \%$ & 66 & $22.3 \%$ \\
\hline VKAs & $|4|$ & $2.9 \%$ & 29 & $20.6 \%$ \\
\hline Fondaparinux & 66 & $1.3 \%$ & 28 & $42.4 \%$ \\
\hline Combination & 81 & $1.7 \%$ & 76 & $93.8 \%$ \\
\hline Total & 4906 & & 1189 & $24.2 \%$ \\
\hline
\end{tabular}

Abbreviations: THR, total hip replacement; TKR, total knee replacement; AT, antithrombotic treatment; VKAs, vitamin $\mathrm{K}$ antagonists.
Among the THR group, 158 patients (2.9\%) were rehospitalized during the year of follow-up for THR after a median time of 229 days (range 161-294), while $28(0.5 \%)$ were for TKR (median 252, range 203-340); within the TKR group, 207 (4.2\%) were rehospitalized for TKR after a median period of 245 days (range 136-324), while $29(0.6 \%)$ were for THR (median 289, range 226-335). It was not possible to determine through ICD9 codes if this second procedure referred to the same or contralateral side.

During the follow-up period, within the THR group, 58 (110 per 10,000 patients) cases of VTE were observed, with a median time of 34 days (range 16-150) after THR discharge; among the TKR group, the cases were 71 (140 per 10,000 patients), with a median time of 21 days (range 15-51) after TKR discharge. Particularly, we observed 520 VTE cases per 10,000 patients among untreated patients and 60 per 10,000 among treated; death rates for any cause were $2.3 \%(3 / 129)$ among patients who experienced VTE and $0.5 \%$ $(52 / 10,260)$ among those who did not experience VTE.

Overall, PTS was observed in five subjects (4.8 per 10,000 patients) while HIT was observed in three subjects (2.9 per 10,000 patients).

\section{Costs}

The median cost for the main THR procedure was $€ 9052.00$ (range $€ 8063.00-€ 9084.96$ ), with a median length of stay of the hospitalization equal to 9 days (range 6-12); for TKR, these values were $€ 9052.00$ (range $€ 8063.00-€ 9084.96$ ), with a median length of stay of 9 days (range $6-10$ ). When the hospitalization was compounded by a cardiovascular event, these values were $€ 9052.00$ (range $€ 8156.00-€ 9084.96$ ) and 9 days (range 7-14) for THR (532 patients, 9.7\%) and $€ 9052.00$ (range $€ 8156.00-€ 9052.00$ ) and 8 days (range 6-10) for TKR (405 patients, 8.3\%). When the hospitalization was compounded by VTE, these values were $€ 9324.00$ (range $€ 9144.72-€ 9324.00$ ) and 16 days (range, 12-18) for THR (28 patients, $0.51 \%$ ) and $€ 9324.00$ (range €8759.00-€9324.00) and 11 days (range 9.0-13.0) for TKR (21 patients, $0.43 \%$ ) (Table 3 ).

Moreover, we observed that the cost for antithrombotic treatment concentrated in the first month after discharge for both surgical sites was in agreement with the duration of antithrombotic treatment presented above; the outpatient services costs, instead, showed a median that amounted to about $€ 20$ for both THR or TKR and for each subperiod considered $(1,3$, and 6 months after hospital discharge) (Table 4).

We also considered the different cost components for patients with and without postoperative complications. 
Table 3 Cost and length of stay for main procedure according to complications

\begin{tabular}{|c|c|c|c|c|}
\hline & \multicolumn{2}{|l|}{ Cost in $€$} & \multicolumn{2}{|l|}{ Length of stay } \\
\hline & Median (p25-p75) & Mean \pm SD & Median (p25-p75) & Mean \pm SD \\
\hline \multicolumn{5}{|l|}{ Overall } \\
\hline THR & $9052.00(8063.00-9084.96)$ & $8733.61 \pm 2227.10$ & $9.0(6.0-12.0)$ & $10.4 \pm 7.9$ \\
\hline TKR & $9052.00(8063.00-9084.96)$ & $8677.23 \pm 1228.52$ & $9.0(6.0-10.0)$ & $9.2 \pm 5.0$ \\
\hline \multicolumn{5}{|c|}{$\mathrm{CV}$ during procedure } \\
\hline THR & $9052.00(8156.00-9084.96)$ & $9317.86 \pm 5681.89$ & $9.0(7.0-14.0)$ & $11.9 \pm 17.7$ \\
\hline TKR & $9052.00(8156.00-9052.00)$ & $8997.47 \pm 1426.23$ & $8.0(6.0-10.0)$ & $10.1 \pm 7.9$ \\
\hline \multicolumn{5}{|c|}{ VTE during procedure } \\
\hline THR & 9324.00 (9144.72-9324.00) & $9788.47 \pm 2363.83$ & $16.0(12.0-18.0)$ & $16.4 \pm 5.5$ \\
\hline TKR & $9324.00(8759.00-9324.00)$ & $9123.10 \pm 1884.56$ & $11.0(9.0-13.0)$ & $11.6 \pm 5.4$ \\
\hline \multicolumn{5}{|c|}{ No complications } \\
\hline THR & $9052.00(8063.00-9084.96)$ & $8665.67 \pm|402.9|$ & $9.0(6.0-12.0)$ & $10.2 \pm 6.1$ \\
\hline TKR & $9052.00(8063.00-9084.96)$ & $8646.06 \pm 1200.55$ & $9.0(6.0-10.0)$ & $9.1 \pm 4.6$ \\
\hline
\end{tabular}

Abbreviations: THR, total hip replacement; TKR, total knee replacement; SD, standard deviation; p25/p75, 25th/75th percentile; CV, cardiovascular event; VTE, venous thromboembolism.

To define the patient with complications, we considered all patients who experienced a rehospitalization for cardiovascular reasons or for VTE during the 6 months after THR/TKR discharge (Table 5).

In particular, patients with complications had total costs (drugs and outpatient services) lower than patients without complications. More specifically, for the THR group, the cost of illness at 1 month amounted to $€ 66.82$ for patients without complications and $€ 40.50$ for patients with complications; the values for the TKR group were, respectively, $€ 66.70$ and $€ 51.74$. Even at 3 months, the related costs seemed to be higher for the group without complications $(€ 112.60$ vs $€ 98.84$ for THR, $€ 115.83$ vs $€ 108.43$ for TKR); at 6 months, these costs seemed to be similar for both groups in analysis.

\section{Discussion}

Among the 10,389 patients with TKR or THR included in the analysis, median duration of antithrombotic treatment was about 22 days for both procedures. It was not possible, based on the administrative databases, to get information about in-hospital treatments, but mean length of stay between surgery and discharge was, overall, 9 days. Even considering this gap of time, the total treatment duration was below the recommended 6-week treatment period; enoxaparin $(37.9 \%)$ and heparin $(36.1 \%)$ were the most prescribed antithrombotic treatments. We also observed a quota of patients without treatment after discharge (13.9\%), similar to other previous studies, ${ }^{13}$ a change of therapy was observed among $22.6 \%$ patients during the 6-month follow-up period. The reason for the switches was not available.

Table 4 Cost of treatments and outpatient specialist services related and not related to THR/TKR

\begin{tabular}{|c|c|c|c|c|c|c|c|c|}
\hline & \multicolumn{2}{|l|}{ Related } & \multirow[t]{2}{*}{$\mathbf{n}$} & \multirow[t]{2}{*}{$\%$} & \multicolumn{2}{|l|}{ Not related } & \multirow[t]{2}{*}{$\mathbf{n}$} & \multirow[t]{2}{*}{$\%$} \\
\hline & Median (p25-p75) & Mean \pm SD & & & Median (p25-p75) & Mean \pm SD & & \\
\hline \multicolumn{9}{|l|}{ Treatment costs } \\
\hline THR at I month & $68.84(34.42-130.76)$ & $63.90 \pm 72.28$ & 4020 & $73.3 \%$ & $30.41(11.83-61.00)$ & $26.76 \pm 88.20$ & 2922 & $53.3 \%$ \\
\hline TKR at I month & $68.84(34.4 \mid-130.00)$ & $69.67 \pm 72.52$ & 3847 & $78.4 \%$ & $32.94(14.04-64.68)$ & $33.53 \pm 96.01$ & 3235 & $65.9 \%$ \\
\hline THR at 3 months & $68.84(32.91-135.44)$ & $81.13 \pm 94.53$ & 4525 & $82.5 \%$ & $65.27(26.5|-| 28.31)$ & $80.19 \pm 195.71$ & 4176 & $76.2 \%$ \\
\hline TKR at 3 months & $73.48(32.91-136.00)$ & $83.87 \pm 89.10$ & 4189 & $85.4 \%$ & 74.60 (33.55-|40.9I) & $96.80 \pm 235.28$ & 4254 & $86.7 \%$ \\
\hline THR at 6 months & $73.00(34.12-137.68)$ & $90.11 \pm 111.42$ & 4655 & $84.9 \%$ & |23.7| (46.78-244.00) & $161.65 \pm 312.09$ & 4547 & $82.9 \%$ \\
\hline TKR at 6 months & $75.42(34.13-137.68)$ & $90.97 \pm 97.88$ & 4289 & $87.4 \%$ & |42.06 (6I.|15-265.24) & $188.95 \pm 347.06$ & 4489 & $91.5 \%$ \\
\hline \multicolumn{9}{|c|}{ Outpatient specialist services costs } \\
\hline THR at I month & $23.80(9.60-54.93)$ & $22.11 \pm 70.64$ & 2205 & $40.2 \%$ & $22.21(10.67-40.60)$ & $15.73 \pm 89.12$ & 1904 & $34.7 \%$ \\
\hline TKR at I month & $21.20(7.20-44.50)$ & $23.24 \pm 76.49$ & 2023 & $41.2 \%$ & $20.08(8.50-38.04)$ & $21.37 \pm 248.84$ & 1814 & $37.0 \%$ \\
\hline THR at 3 months & $46.98(22.98-82.45)$ & $69.42 \pm 125.22$ & 4595 & $83.8 \%$ & 40.30 (19.72-88.55) & $63.11 \pm 243.79$ & 3739 & $68.2 \%$ \\
\hline TKR at 3 months & $43.22(23.29-86.13)$ & $75.11 \pm 137.91$ & 4049 & $82.5 \%$ & 40.84 (19.75-90.96) & $78.60 \pm 791.55$ & 3398 & $69.3 \%$ \\
\hline THR at 6 months & $71.05(37.37-126.30)$ & $104.05 \pm 159.55$ & 4947 & $90.2 \%$ & $81.60(36.05-172.64)$ & $147.18 \pm 519.14$ & 4481 & $81.7 \%$ \\
\hline TKR at 6 months & $65.58(32.90-127.70)$ & $111.52 \pm 176.63$ & 4449 & $90.7 \%$ & $82.52(35.27-186.17)$ & $169.68 \pm 1324.79$ & 4096 & $83.5 \%$ \\
\hline
\end{tabular}

Abbreviations: THR, total hip replacement; TKR, total knee replacement; SD, standard deviation; p25/p75, 25th/75th percentile. 
Table 5 Costs (drugs, outpatient specialist services, hospitalizations) for patients with and without complications: first 6 months of follow-up

\begin{tabular}{|c|c|c|c|c|c|c|}
\hline \multirow[t]{2}{*}{ THR/TKR } & \multirow[t]{2}{*}{ Complications } & & \multicolumn{2}{|l|}{ Drugs and OSS } & \multicolumn{2}{|l|}{ Hospitalizations } \\
\hline & & & Median (p25-p75) & Mean \pm SD & Median (p25-p75) & Mean \pm SD \\
\hline \multirow[t]{4}{*}{ THR } & Without CC & $\mathrm{n}, \%$ & $4626(84.4)$ & & & \\
\hline & & At I month & $66.82(18.36-130.80)$ & $90.45 \pm 106.20$ & & \\
\hline & & At 3 months & I I 2.60 (57.22-I88.30) & $153.27 \pm 161.30$ & & \\
\hline & & At 6 months & |4I.85 (78.86-234.|I) & $194.74 \pm 201.03$ & & \\
\hline \multirow[t]{4}{*}{ THR } & With CC & $\mathrm{n}, \%$ & $857(15.6)$ & & & \\
\hline & & At I month & $40.50(0.00-89.21)$ & $62.89 \pm 82.26$ & $3920.00(1580.34-5250.00)$ & $3782.67 \pm 3632.44$ \\
\hline & & At 3 months & $98.84(51.72-166.73)$ & $136.32 \pm 138.14$ & $4900.00(3157.96-6261.00)$ & $5473.70 \pm 4988.68$ \\
\hline & & At 6 months & I 47.62 (79.40-232.13) & $191.20 \pm 175.58$ & $5145.00(3500.00-7177.50)$ & $6555.87 \pm 6603.28$ \\
\hline \multirow[t]{4}{*}{ TKR } & Without CC & $\mathrm{n}, \%$ & $4174(85.1)$ & & & \\
\hline & & At I month & $66.70(14.04-129.35)$ & $95.87 \pm 107.96$ & & \\
\hline & & At 3 months & II 5.83 (55.10-197.33) & $158.80 \pm 162.29$ & & \\
\hline & & At 6 months & $|46.1|(78.40-238.06)$ & $199.64 \pm 197.65$ & & \\
\hline \multirow[t]{4}{*}{ TKR } & With CC & $\mathrm{n}, \%$ & $732(14.9)$ & & & \\
\hline & & At I month & $51.74(4.00-103.26)$ & $76.77 \pm 96.80$ & $4165.00(2250.00-5250.00)$ & $3966.61 \pm 3188.19$ \\
\hline & & At 3 months & $108.43(54.10-179.25)$ & $159.98 \pm 172.72$ & $4900.00(3338.94-5800.00)$ & $5188.32 \pm 4262.58$ \\
\hline & & At 6 months & I47.77 (88.08-253.II) & $217.97 \pm 223.98$ & $5000.00(3500.00-6550.00)$ & $5850.20 \pm 4738.77$ \\
\hline
\end{tabular}

Abbreviations: THR, total hip replacement; TKR, total knee replacement; OSS, outpatient specialist services; SD, standard deviation; p25/p75, 25th/75th percentile.

Overall, VTE was observed among 129 patients (124.2 per 10,000), and median time between THR/TKR discharge and VTE was 23 days (range 15-84), suggesting that a longer treatment period could be appropriate. Hospitalizations for VTE totaled $€ 654,286.41$. PTS is a rare condition, ${ }^{18}$ and was observed in five patients $(4.8$ per 10,000). HIT is an uncommon ${ }^{19-21}$ but potentially devastating complication; it was observed in three patients (2.9 per 10,000).

The median cost for both THR and TKR procedures amounted to about $€ 9000.00$, with a median length of stay for hospitalization of 9 days; 49 patients experienced VTE during the index procedure. The cost increased to over $€ 9300.00$ and the length of stay increased by $22 \%$ (11 days) for TKR and $78 \%$ (16 days) for THR.

The cost for antithrombotic treatment concentrated in the first month after discharge, while outpatient services costs amounted to $€ 20$ for each subperiod in analysis, suggesting a continuity of controls during the first 6 months of postoperative follow-up. We also observed that patients with complications after hospital discharge had costs for drugs and outpatient services lower than patients without complications, suggesting the need for an appropriate pharmacological prevention.

The main study limitations were related to the type of databases used. First of all, in-hospital therapy was not included, which led to an underestimation of the total length of treatment. Clinical characteristics of the patients were not available, and consequentially we were unable to retrieve the cause for treatment switches. Moreover, we could retrieve only adverse events that needed a hospitalization (ie, bleeding, HIT, VTE), leading to an underestimation of their incidence.

\section{Conclusion}

Our findings are that in clinical practice, the majority of the patients in analysis seemed to be adequately treated. VTE was observed among 124.2 per 10,000 patients. In addition to the impact of venous thromboembolism on morbidity and mortality, the economic burden of the management of VTE was considerable: among the 129 patients who experienced VTE and needed hospitalization, the total cost for hospital admission was over $€ 600,000.00$.

The use of administrative databases showed a high reliability in that we were able to retrieve the whole medical history and treatment pattern of each single patient; moreover, the linkage among administrative databases is simple to perform and does not require a specific epidemiological organization; thus the cost is very low.

A continuous monitoring of antithrombotic treatment in real practice could contribute to improving the appropriateness of antithrombotic treatment as well as the patient outcomes.

\section{Disclosure}

This study was sponsored by Bristol-Myers Squibb. Luca Degli Esposti, Stefano Buda, Diego Sangiorgi, and Ezio Degli Esposti are employees of CliCon Health, Economics and Outcomes Research who were paid consultants to 
Bristol-Myers Squibb in connection with the development of this manuscript.

\section{References}

1. Bozic KJ, Vail TP, Pekow PS, Maselli JH, Lindenauer PK, Auerbach AD Does aspirin have a role in venous thromboembolism prophylaxis in total knee arthroplasty patients? J Arthroplasty. 2010;25(7):1053-1060.

2. Bjørnarå BT, Gudmundsen TE, Dahl OE. Frequency and timing of clinical venous thromboembolism after major joint surgery. $J$ Bone Joint Surg Br. 2006;88(3):386-391.

3. Clayton RA, Gaston P, Watts AC, Howie CR. Thromboembolic disease after total knee replacement:experience of 5100 cases. Knee. 2009;16(1):18-21.

4. Warwick D, Friedman RJ, Agnelli G, et al. Insufficient duration of venous thromboembolism prophylaxis after total hip or knee replacement when compared with the time course of thromboembolic events: findings from the Global Orthopaedic Registry. $J$ Bone Joint Surg Br. 2007;89(6):799-807.

5. Wells PS, Borah BJ, Sengupta N, Supina D, McDonald HP, Kwong LM. Analysis of venous thromboprophylaxis duration and outcomes in orthopedic patients. Am J Manag Care. 2010;16(11):857-863.

6. Kwong LM, Kistler KD, Mills R, Wildgoose P, Klaskala W. Thromboprophylaxis, bleeding and post-operative prosthetic joint infection in total hip and knee arthroplasty:a comprehensive literature review. Expert Opin Pharmacother. 2012;13(3):333-344.

7. Penning-van Beest FJ, Overbeek JA, Meijer WM, et al. Venous thromboembolism prophylaxis after total knee or hip replacement: treatment pattern and outcomes. Pharmacoepidemiol Drug Saf. 2011;20(9):972-978

8. Mismetti P, Zufferey P, Pernod G, et al. Thromboprohylaxis in orthopedic surgery and traumatology. Ann Fr Anesth Reanim. 2005; 24(8):871-889.

9. Samama MM. Advances and perspectives in the prevention of venous thromboembolic disease. Arch Mal Coeur Vaiss. 2001;94(Suppl 11): 1313-1317. French.

10. European Medicines Agency. Guideline on clinical investigation of medicinal products for prophylaxis of high intra- and post-operative venous thromboembolic risk. 2012. Available from: http://www.ema. europa.eu/docs/en_GB/document_library/Scientific_guideline/2012/05/ WC500127902.pdf. Accessed November 30, 2012.
11. Cohen AT, Tapson VF, Bergmann JF, et al. Venous thromboembolism risk and prophylaxis in the acute hospital care setting (ENDORSE study): a multinational cross sectional study. Lancet. 2008;371(9610): 387-394.

12. Schiff RL, Kahn SR, Shrier I, et al. Identifying orthopedic patients at high risk for venous thromboembolism despite thromboprophylaxis. Chest. 2005;128(5):3364-3371.

13. Bambrah RK, Pham DC, Zaiden R, Vu H, Tai S. Heparin-induced thrombocytopenia. Clin Adv Hematol Oncol. 2011;9(8):594-599.

14. Gras-Champel V, Brenet-Dufour V, Moragny J, et al. Quantification of the part allocated to the preventability of vitamin $\mathrm{K}$ antagonists therapy bleeding events. Therapie. 2010;65(3):261-268.

15. Kapoor A, Chuang W, Radhakrishnan N, et al. Cost effectiveness of venous thromboembolism pharmacological prophylaxis in total hip and knee replacement: a systematic review. Pharmacoeconomics. 2010; 28(7):521-538.

16. Madhusudhan T, et al. Gastric protection and gastrointestinal bleeding with aspirin thromboprophylaxis in hip and knee joint replacements. Ann R Coll Surg Engl. 2008;90(4):332-335.

17. Park JJ, Slover JD, Stuchin SA. Recurrent hemarthrosis in a hemophilic patient after revision total knee arthroplasty. Orthopedics. 2010 33(10):771.

18. Fitzgerald SJ, McAndrew CM, Kraay MJ, Goldberg VM. Incidence of postthrombotic syndrome in patients undergoing primary total hip arthroplasty for osteoarthritis. Clin Orthop Relat Res. 2011;469(2): $530-534$.

19. Warkentin TE, Levine MN, Hirsh J, et al. Heparin-induced thrombocytopenia in patients treated with low-molecular-weight heparin or unfractionated heparin. N Engl J Med. 1995;332(20):1330-1335.

20. Girolami B, Prandoni P, Stefani PM, et al. The incidence of heparininduced thrombocytopenia in hospitalized medical patients treated with subcutaneous unfractionated heparin: a prospective cohort study. Blood. 2003;101(8):2955-2959.

21. Morris TA, Castrejon S, Devendra G, Gamst AC. No difference in risk for thrombocytopenia during treatment of pulmonary embolism and deep venous thrombosis with either low-molecular-weight heparin or unfractionated heparin:a metaanalysis. Chest. 2007;132(4):1131-1139.
ClinicoEconomics and Outcomes Research

\section{Publish your work in this journal}

ClinicoEconomics \& Outcomes Research is an international, peerreviewed open-access journal focusing on Health Technology Assessment, Pharmacoeconomics and Outcomes Research in the areas of diagnosis, medical devices, and clinical, surgical and pharmacological intervention. The economic impact of health policy and health systems

\section{Dovepress}

organization also constitute important areas of coverage. The manuscript management system is completely online and includes a very quick and fair peer-review system, which is all easy to use. Visit http://www.dovepress.com/testimonials.php to read real quotes from published authors. 